\title{
Minimizing the Number of Aeroallergen Extracts in Skin Prick Test in IgE-Mediated Allergic Disorders in Both Adults and Children in Jordan
}

\author{
Lubna Khreesha $\mathbb{D}^{\prime}$ \\ Mohammad Ghunaim' \\ Mohamad- \\ Amin Ramzown (D) \\ Mohammad Alkhoujah (D) ${ }^{2}$ \\ Mohamed Tawalbeh (D) \\ Montaha Al-lede (iD ${ }^{3}$ \\ Tareq Kanaan $\mathbb{D}^{4}$ \\ Mustafa Alrabayah (1D $)^{5}$ \\ Suhaib Eid' \\ 'Otolaryngology, Department of Special \\ Surgeries, Faculty of Medicine, The \\ University of Jordan, Amman, Jordan; \\ ${ }^{2}$ Faculty of Medicine, The University of \\ Jordan, Amman, Jordan; ${ }^{3}$ Department of \\ Pediatrics, Faculty of Medicine, The \\ University of Jordan, Amman, Jordan; \\ ${ }^{4}$ Department of Neurosurgery, Faculty of \\ Medicine, The University of Jordan, \\ Amman, Jordan; ${ }^{5}$ Department of \\ Anesthesia and Intensive Care, The \\ University of Jordan, Amman, Jordan
}

This article was published in the following Dove Press journal: Journal of Asthma and Allergy

Background: Skin prick test (SPT) is the most common diagnostic procedure that is performed considering the history of aeroallergen sensitivity among patients. Moreover, it is important to identify the diagnostic and therapeutic benefits of allergen's number in skin prick testing in both adults and children.

Objective: The present study aims to detect the minimum number of allergens used in SPT to identify $95 \%$ of sensitized patients in both pediatric and adult age groups in Jordan.

Patients and Methods: Retrospective analysis of a 20 allergen extracts SPT results for 2253 patients (aged 8 and above) was conducted to assess the minimum number of allergen extracts needed to identify $95 \%$ of the sensitized patients in both adults and children.

Results: The results showed that $50.9 \%$ of the pediatric group was sensitized to at least one aeroallergen extract in comparison to $48.3 \%$ of the adult group. Only 8 allergen extracts were necessary to identify $95 \%$ of the sensitized patients which are olive pollen, Dermatophagoides pteronyssinus, Salsola kali, 4 cereals, Wall pellitory, Dermatophagoides farinae, Cypress and mugwort. Same number was needed in children but with the replacement of mugwort with alternaria to achieve a similar result.

Conclusion: The study concluded that only 8 allergen extracts were needed for detecting $95 \%$ of sensitized patients (both pediatrics and adults) in SPT. The authors proposed a twostage screening: stage 1 includes the minimum number of allergen extracts to detect $95 \%$ of sensitized patients and stage 2 for the patients who tested negative in stage 1 which will include a broader allergen extracts panel excluding those which were already tested in stage 1.

Keywords: allergic, diagnosis, hypersensitivity, rhinitis

\section{Introduction}

A major worldwide health problem, allergic rhinitis (AR) affects patients of all age groups, affecting at least $20 \%$ of the world population with a higher prevalence in the pediatric group. ${ }^{1,2} \mathrm{AR}$ has varying prevalence in different regions and has shown its increased incidence in the past few years, especially in Jordan. ${ }^{3,4}$ Moreover, it has a significant impact on quality of life, with an adverse effect on the patient's ability to work. ${ }^{1}$ In addition, these diseases may lead to sleep disorders in $66 \%$ of adults and $43 \%$ of pediatric patients causing daytime hypersomnolence. ${ }^{5}$ The proper diagnosis and detection of specific allergen hypersensitivity can help control AR and prevent other pulmonary diseases. ${ }^{6}$ The allergen specific IgE can be assessed in both serum testing and skin prick testing. ${ }^{7,8}$ However, the skin prick test
Correspondence: Mohammad Ghunaim Tel +962796418585

Email Mohammad@Ghunaim.org 
(SPT) remains the standard test used to diagnose IgEmediated allergic disease. ${ }^{9}$ When combined with proper history, physical examination and medical investigation, SPT is a rapid test that needs approximately $20-30 \mathrm{~min}-$ utes which could yield a sensitivity of at least $80 \%{ }^{10,11}$ A meta-analysis done by Navis in 2016 concluded that SPT is an accurate tool for distinguishing allergic rhinitis patients at a sensitivity of $68-100 \%$ and specificity of $70-91 \%{ }^{12}$ Thus, SPT helps in documenting sensitization for epidemiological purposes, along with identifying and avoiding specific allergens in clinical practice. ${ }^{7,13}$ Any allergen responsible for more than $2 \%$ of patient's sensitization is worth being included in the standard test battery. ${ }^{14}$

The dramatic increase in the prevalence of allergic disease burdens the global public health. The number of allergens used in SPT are significantly affected by economical and psychological factors. Few of the previous studies have provided encouraging results to minimize the size of test battery. ${ }^{14,15}$ However, no such studies have been conducted in the region of Jordan. SPT is considered the most common diagnostic procedure that is performed considering the history of aeroallergen sensitivity among the patients. It is important to identify the diagnostic and therapeutic benefits of skin prick testing on the patients and the health-care system. Therefore, the study aims to detect the minimum number of allergens that should be used in SPT to identify $95 \%$ of sensitized pediatric and adult patients.

\section{Patients and Methods}

\section{Study Design and Setting}

A retrospective study was conducted over a period of 2 years in the University of Jordan Otolaryngology clinic, which is a leading center in both primary and tertiary healthcare in the region.

\section{Study Population}

The results of 2253 patients diagnosed at our institute with IgE-mediated allergic disorders like (allergic rhinitis, conjunctivitis and bronchial asthma) were retrospectively included, who were aged between 8 and 83 years. The list of medications taken by the patients was reviewed before undergoing the testing procedure. All patients that were tested in our department were included except those who demonstrated signs of skin dermographism, patients on medications that affects the SPT results including antihistamines, beta blockers or local steroids on tested area. The patients were classified into two groups and both groups were compared to determine the number of allergen extracts needed to identify $95 \%$ of sensitized patients.

- Adult group - Individuals above the age of 18 years

- Pediatrics - Individuals below the age of 18 years

\section{Study Procedure (Skin Prick Testing)}

A total of 20 allergen extracts were used in the standard skin prick testing panel that included: 1.Olive pollen 2 . Dermatophagoides pteronyssinus 3.Salsola Kali 4.12 grasses pollen (bent grass, bermuda grass, bromus, cocksfoot, meadow fescue, meadow grass, oat grass, rye-grass, sweet-vernal grass, timothy wild oat and Yorkshire fog) 5.4 cereals (oat, wheat, barley and maze) 6. Wall pellitory 7.Dermatophagoides farina 8.Cypress 9.Nettle 10 . Chenopodiaceae 11.Privet 12.Pine 13.Sorrel 14. Aspergillus 15.Compositae 16.Alternaria 17.Fagaceae 18. Penicillium 19.Mugwort 20.Cladosporium. The total number of tested allergens came out to be 34 as some allergens were a mixture of extracts. The kit used to conduct the test was a standardized extract kit (Stallergenes, Antony, Hauts-de-Seine, France). A solution of $10 \mathrm{mg} / \mathrm{mL}$ of histamine phosphate was used as a positive control and applied on both forearms of the patients. A negative control of sterile $0.9 \%$ saline was used. A total of 12 skin pricks were done on each forearm (10 allergens, a negative saline control and a positive control). Patients were re-evaluated 30 minutes after applying the allergens, where a wheal diameter of $3 \mathrm{~mm}$ and more was considered positive and less than $3 \mathrm{~mm}$ was considered negative. Any subject with at least one positive result was considered sensitized.

All testing was conducted by the same lab technician in the same allergy lab, under similar standardized conditions. It is important to note that positive skin test alone is not enough to diagnose allergy; therefore, symptoms such as rhinorrhea, excessive sneezing, nasal blockage, nasal itching, eye itching or cough appearing after being exposed to the allergen were also demonstrated by history taking in the clinic.

\section{Statistical Analysis}

The first step was to identifying the most common aeroallergen extract tested positive in the total study population which was olive pollen, then a stepwise conditional approach was applied to determine the allergen causing the highest prevalence of sensitization in the group of 
those that were not sensitized to olive pollen. For example, a total of 1101 patients tested positive in SPT, 568 of them tested positive for olive pollen and 533 were not sensitized to it. These 533 patients' results were studied to identify the subsequent aeroallergens in order to identify the next most common allergen after olive pollen which was Dermatophagoides pteronyssinus in 201 of patients. Then, these 201 patients were excluded leaving 332 patients to be tested (Table 1). This process of stepwise conditional approach was repeated until all allergen extracts were studied. This process was done for both the pediatric group and adult group independently. They were then ordered from the highest to lowest prevalence, where the most prevalent was considered as a reference point. Cumulative percent of sensitization were calculated till $95 \%$ of sensitized patients were covered and then repeated again till $100 \%$ of sensitized patients were identified, see Tables 2 and 3. The statistical analysis was done using SPSS 20.0 software (Chicago, IL, USA). Counting of the variables and frequencies was done along with a literature-based analysis of descriptive and cumulative percentages.

Table I Prevalence of Sensitization, Allergen Ordered from the Most Prevalent to the Allergen with the Least Increase in Identifying Additional Sensitized Subjects

\begin{tabular}{|l|l|l|}
\hline \multirow{2}{*}{ Allergen } & \multicolumn{2}{|l|}{ Sensitized Patients } \\
\cline { 2 - 3 } & N & $\begin{array}{l}\text { \% from Total Sensitized } \\
\text { (I I O I Patients) }\end{array}$ \\
\hline Olive pollen & & 52.15 \\
Dermatophagoides pteronyssinus & 568 & 18.26 \\
Salsola kali & 20 I & 10.17 \\
Cereals & 112 & 7.27 \\
Wall pellitory & 80 & 2.99 \\
Dermatophagoides farinae & 33 & 2.27 \\
Cypress & 25 & 1.90 \\
Mugwort & 21 & 1.45 \\
I2 Grasses pollen & 16 & 1.09 \\
Nettle & 12 & 0.64 \\
Chenopodiaceae & 7 & 0.54 \\
Pine & 6 & 0.45 \\
Penicillium & 5 & 0.45 \\
Sorrel & 5 & 0.36 \\
Alternaria & 4 & 0.27 \\
Private & 3 & 0.18 \\
Fagaceae & 2 & 0.09 \\
Compositae & 1 & 0 \\
Aspergillus & 0 & 0 \\
Cladosporium & 0 & 0 \\
\hline
\end{tabular}

Table 2 Prevalence of Allergen Sensitization in the Pediatric Group in Order of Contribution to Total Pediatric Sensitized Number

\begin{tabular}{|l|l|l|}
\hline \multicolumn{1}{|l|}{ Allergen } & $\begin{array}{l}\text { Pediatrics } \\
\text { Sensitized Patient } \\
\text { (\% of Total } \\
\text { Sensitized Pediatric } \\
\text { Patients) }\end{array}$ & $\begin{array}{l}\text { Cumulative } \\
\text { Percentage } \\
\text { (\%) }\end{array}$ \\
\hline \multicolumn{2}{|l|}{} \\
\hline Total N=252 & $116(46.03 \%)$ & 46.03 \\
\hline I. Olive pollen & $51(20.24 \%)$ & 66.27 \\
2.Dermatophagoides pteronyssinus & $26(10.32 \%)$ & 76.59 \\
3. Salsola kali & $19(7.54 \%)$ & 84.13 \\
4. Cereals & $9(3.57 \%)$ & 87.7 \\
5.Dermatophagoides farinae & $7(2.78 \%)$ & 90.48 \\
6. Wall pellitory & $7(2.78 \%)$ & 93.26 \\
7. Cypress & $5(1.98 \%)$ & 95.24 \\
8. Alternaria & $4(1.59 \%)$ & 96.83 \\
9. I2 grasses pollen & $3(1.19 \%)$ & 98 \\
10. Nettle & $2(0.79 \%)$ & 98.8 \\
II. Mugwort & $1(0.396 \%)$ & 99.2 \\
12. Pine & $1(0.396 \%)$ & 99.6 \\
13. Privet & $1(0.396 \%)$ & 100 \\
14. Aspergillus & $0(0 \%)$ & 100 \\
15. Chenopodiaceae & $0(0 \%)$ & 100 \\
16. Penicillium & $0(0 \%)$ & 100 \\
17. Sorrel & $0(0 \%)$ & 100 \\
18. Fagaceae & $0(0 \%)$ & 100 \\
19. Compositae & $0(0 \%)$ & 100 \\
20. Cladosporium &
\end{tabular}

\section{Ethical Consideration}

The study was proceeded after obtaining the approval from the IRB board of the University of Jordan on the 24th of February 2016 (approval reference number: 641/146/TK.) An oral informed consent, which was approved by the IRB board, was provided by all patients that were included in the testing procedure, after providing a detailed explanation of the nature of the SPT. If the patient was under the legal age, an informed consent of the legal guardian was taken for participating in the study and for undergoing the test.

\section{Results}

The study included 2253 patients in total, among which $22 \%$ were children and adolescence (ages 8-18 years). These individuals were further divided into $47.5 \%$ males and $52.5 \%$ females, with an average age of 14 years. The adult group comprised of $78 \%$ of the study population, among which $37 \%$ were males and $63 \%$ females with a total average age of 35 years (Table 4). The results showed that 1101 patients $(48.9 \%)$ of all the study 
Table 3 Prevalence of Allergen Sensitization in the Adult Group in Order of Contribution to Total Adult Sensitized Number

\begin{tabular}{|l|l|l|}
\hline Allergen & $\begin{array}{l}\text { Adult Sensitized Patient } \\
\text { (\% of Total Sensitized } \\
\text { Pediatric Patients) }\end{array}$ & $\begin{array}{l}\text { Cumulative } \\
\text { Percentage } \\
\text { (\%) }\end{array}$ \\
\hline Total N=849 & \multicolumn{2}{|l|}{} \\
\hline Olive pollen & $452(53.23 \%)$ & 53.23 \\
Dermatophagoides farinae & $111(13.1 \%)$ & 66.33 \\
Salsola kali & $92(10.83 \%)$ & 77.16 \\
Cereals & $69(8.13 \%)$ & 85.29 \\
Dermatophagoides & $41(4.83 \%)$ & 90.12 \\
pteronyssinus & & \\
Wall pellitory & $23(2.71 \%)$ & 92.83 \\
Mugwort & $16(1.88 \%)$ & 94.71 \\
Cypress & $12(1.41 \%)$ & 96.12 \\
I2 Grasses pollen & $8(0.94 \%)$ & 97.06 \\
Chenopodiaceae & $5(0.59 \%)$ & 97.65 \\
Nettle & $4(0.47 \%)$ & 98.12 \\
Pine & $4(0.47 \%)$ & 98.59 \\
Penicillium & $4(0.47 \%)$ & 99.06 \\
Sorrel & $4(0.47 \%)$ & 99.53 \\
Fagaceae & $2(0.24 \%)$ & 99.77 \\
Alternaria & $1(0.12 \%)$ & 99.88 \\
Privet & $1(0.12 \%)$ & 100 \\
Compositae & $0(0 \%)$ & 100 \\
Aspergillus & $0(0 \%)$ & 100 \\
Cladosporium & $0(0 \%)$ &
\end{tabular}

population were sensitized to at least one allergen extract, among which 849 were adult patients $(48.3 \%$ of the adult group) and 252 pediatric patients $(50.9 \%$ of the pediatric group). Moreover, 568 patients ( $25.2 \%$ of the total population group) were sensitized to olive pollen alone which makes it the most prevalent allergen in Jordan. This is equal to $52 \%$ of the sensitized group (568 out of 1101). Olive pollen was used as a reference point, to which the cumulative effect of other allergens was added to detect sensitized individuals. The next step was to identify the second most prevalent allergen affecting the sensitized population after excluding those also sensitized to olive pollen. Dermatophagoides Pteronyssinus was the second most prevalent that identified $18.3 \%$ (201 out of 1101) of the sensitized group. Again, this was done to the remaining 18 allergens to identify the percentage of each allergen being added to the sensitized group, after excluding its cross sensitivity with the previous allergens (Table 1).

The final step was adding the cumulative percentage of each allergen in a stepwise manner, until $95 \%$ of the sensitized group was achieved for adult (Table 2) and pediatric (Table 3) groups. Five allergens (olive pollen, Dermatophagoides farinae, S. kali, 4 cereals mix and Dermatophagoides pteronyssinus) were needed to detect $90 \%$ of adult sensitized patients. Eight allergens were needed in the adult group (olive pollen, Dermatophagoides farinae, S. kali, 4 cereal mix, Wall pellitory, Dermatophagoides pteronyssinus, Cypress and mugwort) to achieve a $95 \%$ yield and the replacement of mugwort with alternaria in the pediatric group was needed to achieve a similar result (Table 2). Interestingly, in the pediatric group, 14 allergens were needed to detect $100 \%$ of the sensitized patients, which was less than the adult group that needed 17 allergens. The results have also shown that some allergens had no effect on increasing prevalence rate.

\section{Discussion}

Skin prick test remains the gold standard test for confirming the diagnosis of allergic rhinitis. ${ }^{9,12}$ It is a fast and easy test that can be done in the outpatient setting. ${ }^{11}$ SPT has high rates of both sensitivity and specificity for inhaled allergens. ${ }^{10,12,16}$ The American Academy of Otolaryngology - Head and Neck Surgery Foundation (AAO-HNSF) recommends performing a specific IgE test (blood or skin) for symptomatic allergic rhinitis patients to confirm the diagnoses and improve prognosis ${ }^{13}$ The standard SPT in Jordan contains 20 aeroallergen extracts, which we aim to reduce hoping to cut down the cost and the complications of the procedure.

One of the main contradictions of SPT is that it should not be performed among the patients with increased risk of developing an anaphylactic shock. Using multiple allergens during SPT also increases the risk of a generalized allergic reaction in the pediatric group. ${ }^{17}$ Thus using

Table 4 Study Population Characteristics

\begin{tabular}{|c|c|c|c|c|c|}
\hline \multirow[t]{2}{*}{ Group } & \multicolumn{3}{|l|}{ Age (Years) } & \multicolumn{2}{|c|}{ Gender, \% (n) } \\
\hline & Mean士 SD & Median & Interquartile Range & Male & Female \\
\hline Whole group $(n=2253)$ & $30 \pm 14$ & 28 & $20-40$ & 39.4 (887) & $60.6(1366)$ \\
\hline Pediatric group $(n=495)$ & $14.4 \pm 2.6$ & 15 & $13-17$ & $47.5(235)$ & $52.5(260)$ \\
\hline Adult group $(n=1758)$ & $34.9 \pm 12.7$ & 20 & $24-34$ & $37.1(652)$ & $62.9(1106)$ \\
\hline
\end{tabular}


a smaller battery of allergens could lower this risk. It is also not possible to conduct the skin prick test among patient suffering from certain skin conditions such as acute or chronic urticarial, dermographism, and cutaneous mastocytosis. This is due to the false-positive results that could lead to improper management. Another downside to performing SPT is its poor sensitivity for food allergens $(20-60 \% .)^{16}$ Furthermore, the fear of multiple needle pricks is another factor that can lead to the patient refusing to undergo the test. ${ }^{18}$ Finally, a major drawback to the test is that the result outcomes may vary based on the manufacturer of the used products. Regardless of these drawbacks, it remains the standard method for diagnosis of IgE-mediated allergies. ${ }^{10,13,19}$

The present study was conducted among 2253 patients, who were clinically suspected to have IgE-mediated allergic diseases and underwent the standard SPT with 20 allergen extracts. The authors proposed a two staged SPT to optimize the health costs along with providing individualized therapy and diagnosis to all sensitized patients. This would be done starting with a first stage test using the minimum number of allergens and detecting $95 \%$ of sensitized patients. Then a second stage that included all those who tested negative in the first stage (only $5 \%$ of the first stage group) with a broader spectrum of allergens (excluding the allergen that were tested in the first stage). This method is likely to decrease the cost of using unnecessary allergens and needle trauma associated with the standard SPT.

It was found that eight allergens in adult groups were enough in detecting $95 \%$ of the sensitized patients in both groups; however, the replacement of mugwort with alternaria was needed to detect $95 \%$ of the sensitized pediatric patients. Moreover, 17 allergens out of 20 were required to detect $100 \%$ of sensitized patients in the whole population. Only 14 allergens were needed to detect $100 \%$ of sensitized pediatric group, unlike the adult group which again needed 17 allergens similar to the whole study population.

So, in adults we propose that in first stage test to test for only 8 allergen extracts which will detect $95 \%$ of sensitized patients and will reduce the skin pricking by $60 \%$ (8 allergen extracts, one positive control and one negative control done in one forearm) in comparison to the standard in our department (24 skin pricking as described in the SPT section), in only none sensitized patient that we will proceed to test for the broader panel which includes only 12 allergen extracts after excluding the already tested in the first stage. The same numbers and steps are applied to pediatric age group.
The focus of this study was on the different allergens involved in sensitization of both pediatrics and adults, not on the clinical importance of sensitization. For example, the symptoms related to each allergen were tested in a different study within the department. ${ }^{20-22}$

There was no difference between the numbers of allergens needed to detect $95 \%$ of sensitized patients in both age groups; however, there was a difference in the type of allergens. Other studies have also reported a difference of allergen sensitivity in different age groups. ${ }^{23}$ These results are consistent with previous studies conducted in several different countries stating that only a small panel of allergens was enough to identify most sensitized patients..$^{9,14,15,24}$ On the other hand, a similar study done on children and adolescent between age of 2 and 18 years by Sahiner et al showed that the number of allergens needed to detect patient's sensitivity was decreasing with increase in age; preschool children needed more allergens to detect $95 \%$ sensitization than school children and adolescent. ${ }^{15}$ This difference may be attributed to the fact that our pediatric study population only included patients between the age of 8 and 18 and not those below the age of 8 .

The percentage of allergic patients affected by a certain allergen varies from country to another, many of them showing high rate of sensitivity to house dust mites ${ }^{18,21,25,26}$ In 2011 the most common allergen to test positive in Jordan was grass pollen mix (51.4\%), followed by "thistleweed" (46.9\%) then olive tree pollen $(45.3 \%) .{ }^{21}$ Some results like the high prediction rate of olive pollen among all sensitized patients $(51.6 \%)$ were expected. However, other allergens showed unexpectedly lower involvement as compared to different studies performed for similar allergy (mold and yeast allergies). ${ }^{14,15}$ There was a significant reaction between Dermatophagoides farinaecross and Dermatophagoides pteronyssinus; however, it was less evident as compared to the previous studies. ${ }^{14,15}$

\section{Limitations}

The study results are limited because the pediatric and adult group participants were not distributed equally. Moreover, conducting a study in one center fails to represent the population because it comprises of $40 \%$ of the total Jordanian population living in the capital city Amman. This study would have been of more power if it included other referral centers throughout the country. In addition, the fact that the study is of a retrospective nature is a limitation by itself. 


\section{Conclusion}

The present study has detected the minimum number of allergens that should be used in SPT for identifying 95\% of sensitized patients in both pediatric and adult age groups to be eight aeroallergens. This is both epidemiologically and clinically utile, where the physicians and patients can identify and avoid the allergen as part of the therapy. The test seems to be more cost effective and less traumatic to the patient because of using smaller number of skin prick test. Moreover, a second stage test in selected patients should be done to diagnose the remaining $5 \%$ of patients missed in stage 1 of SPT. Finally, it is encouraged to conduct similar studies in different countries as allergen sensitivity differ with geographical changes.

\section{Acknowledgments}

The main author and all co-authors are very thankful to all the associated personnel in any reference that contributed in/for the purpose of this research.

\section{Funding}

There is no funding to report.

\section{Disclosure}

The authors report no conflicts of interest for this work.

\section{References}

1. Izquierdo-Domínguez A, Valero AL, Mullol J. Comparative analysis of allergic rhinitis in children and adults. Curr Allergy Asthma Rep. 2013;13(2):142-151.

2. Prasad R, Verma SK, Dua R, Kant S, Kushwaha A, Agarwal S. A study of skin sensitivity to various allergens by skin prick test in patients of nasobronchial allergy. Lung India. 2009;26:70-73. doi:10.4103/0970-2113.53228

3. Katelaris CH, Lee BW, Potter PC, et al. Prevalence and diversity of allergic rhinitis in regions of the world beyond Europe and North America. Clin Exp Immunol. 2012;42(2):186-207.

4. Oncham S, Udomsubpayakul U, Laisuan W. Skin prick test reactivity to aeroallergens in adult allergy clinic in Thailand: a 12-year retrospective study. Asia Pac Allergy. 2018;8(2):e17.

5. Hoyte FCL, Nelson HS. Recent advances in allergic rhinitis. F1000Res. 2018;7.

6. Greiner AN, Hellings PW, Rotiroti G, Scadding GK. Allergic rhinitis. Lancet. 2011;378(9809):2112-2122.

7. Paggiaro PL, Bacci E, Amram DL, Rossi O, Talini D. Skin reactivity and specific IgE levels in the evaluation of allergic sensitivity to common allergens for epidemiological purposes. Clin Exp Allergy. 1986;16(1):49-55.
8. Oppenheimer J, Nelson HS. Skin testing. Ann Allergy Asthma Immunol. 2006;96:S6-12.

9. Heinzerling L, Frew AJ, Bindslev-Jensen C, et al. Standard skin prick testing and sensitization to inhalant allergens across Europe-a survey from the GA2LEN network. Allergy. 2005;60(10):1287.

10. Wagner N, Rudert M. Sensitivity and specificity of standardised allergen extracts in skin prick test for diagnoses of IgE-mediated respiratory allergies. Clin Transl Allergy. 2019;9:8.

11. Frati F, Incorvaia C, Cavaliere C, et al. The skin prick test. $J$ Biol Regul Homeost Agents. 2018;32(1Suppl. 1):19-24.

12. Nevis IF, Binkley K, Kabali C. Diagnostic accuracy of skin-prick testing for allergic rhinitis: a systematic review and meta-analysis. Allergy Asthma Clin Immunol. 2016;12:20.

13. Seidman MD, Gurgel RK, Lin SY, et al. Clinical practice guideline: allergic rhinitis executive summary. Otolaryngol Head Neck Surg. 2015;152(2):197-206.

14. Bousquet PJ, Burbach G, Heinzerling LM, et al. GA2LEN skin test study III: minimum battery of test inhalent allergens needed in epidemiological studies in patients. Allergy. 2009;64(11):1656-1662.

15. Şahiner UM, Civelek E, Yavuz ST, Büyüktiryaki AB, Tuncer A, Şekerel BE. Skin prick testing to aeroallergen extracts: what is the optimal panel in children and adolescents in Turkey? Int Arch Allergy Appl Immunol. 2012;157(4):391-398.

16. Delmoy P, Romano A, Bousquet J. In vivo methods for the study of allergy. In: Adkinson NF, Yunginger JW, Busse WW, Bochner BS, Simons FER, Holgate ST, editors. Middleton's Allergy, Principles and Practice. 7th ed. Philadelphia (PA): Elisevier Inc; 2008:1267-1280.

17. Tawalbeh M, Bulatova N, Aburuz S. Investigation of the impact of aeroallergens sensitization on allergic rhinitis severity. Jordan Med $J$. 2011;171(777):1-22.

18. Aburuz S, Bulatova N, Tawalbeh M. Skin prick test reactivity to aeroallergens in Jordanian allergic rhinitis patients. East Mediterr Health J. 2011;17(7):604-610.

19. Tatar EC, Sürenoğlu UA, Saylam G, Işık E, Ozdek A, Korkmaz H. Is there any correlation between the results of skin-prick test and the severity of symptoms in allergic rhinitis? Am J Rhinol Allergy. 2012;26(1):e37-e39.

20. Wong AG, Lomas JM. Allergy testing and immunotherapy. Pediatr Rev. 2019;40(5):219-228.

21. Wang J, Wu Y, Li J, Huang X, Zhu R. Eight aeroallergen skin extracts may be the optimal panel for allergic rhinitis patients in central China. Int Arch Allergy Immunol. 2017;173:193-198.

22. Liccardi G, Calzetta L, Milanese M, Apicella G, Rogliani P. The possible concomitant use of aeroallergen and food panels for skin prick testing might enhance the risk of generalized allergic reactions in children. Turk J Pediatr. 2019;61(5):815-816.

23. Wright S, Yelland M, Heathcote K, Ng SK, Wright G. Fear of needles-nature and prevalence in general practice. Aust Fam Physician. 2009;38(3):172.

24. Goronfolah L. Aeroallergens, atopy and allergic rhinitis in the Middle East. Eur Ann Allergy Clin Immunol. 2016;48(1):5-21.

25. Irani C, Karam M, Baz Z, Maatouk H, Zaitoun F. Airborne pollen concentrations and the incidence of allergic asthma and rhinoconjunctivitis in Lebanon. Revue Française d'Allergologie. 2013;53 (5):441-445.

26. Farrokhi S, Gheybi MK, Movahed A, et al. Common aeroallergens in patients with asthma and allergic rhinitis living in southwestern part of Iran: based on skin prick test reactivity. Iran J Allergy Asthma Immunol. 2015;14(2):133-138. 


\section{Publish your work in this journal}

The Journal of Asthma and Allergy is an international, peer-reviewed open-access journal publishing original research, reports, editorials and commentaries on the following topics: Asthma; Pulmonary physiology; Asthma related clinical health; Clinical immunology and the immunological basis of disease; Pharmacological interventions and new therapies. The manuscript management system is completely online and includes a very quick and fair peer-review system, which is all easy to use. Visit http://www.dovepress.com/testimonials.php to read real quotes from published authors.

Submit your manuscript here: https://www.dovepress.com/journal-of-asthma-and-allergy-journal 